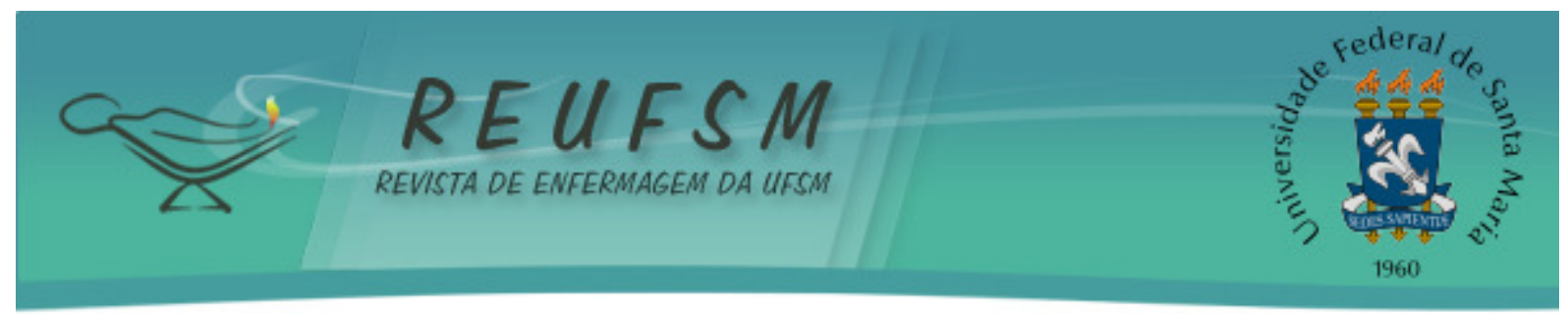

ARTIGO ORIGINAL

\title{
PARTO NORMAL OU CESARIANA? FATORES QUE INFLUENCIAM NA ESCOLHA DA GESTANTE
}

\author{
NORMAL CHILDBIRTH OR CESAREAN? FACTORS AFFECTING THE CHOICE OF \\ PREGNANCY
}

\section{¿PARTO NATURAL O CESÁREA? FACTORES QUE INFLUYEN EN LA ELECCIÓN DE LA MUJER EMBARAZADA}

Susanne Pinheiro Costa e Silva ${ }^{1}$ Renata de Carvalho Gomes Prates ${ }^{2}$ Bruna Queiroz Armentano Campelo ${ }^{3}$

\section{Doi: $10.5902 / 217976928861$}

RESUMO: Objetivo: conhecer fatores que influenciam na decisão da via de parto de gestantes atendidas em uma Unidade de Saúde de Juazeiro-Bahia. Método: pesquisa qualitativa de caráter exploratório-descritivo, desenvolvido com gestantes acompanhadas em Unidade de Saúde entre março e junho de 2010. Participaram da entrevista semiestruturada 12 mulheres grávidas com idade igual ou superior a 18 anos, e para categorização do material utilizou-se análise de conteúdo. Resultados: a maior parte delas optaria pelo parto normal devido à rápida recuperação. A experiência anterior influiu na escolha da via de parto, seja esta da própria gestante ou outrem. Dentre as influências relatadas, destacaram-se: a mãe, profissionais de saúde e a mídia. Avaliaram que as informações perpassadas no pré-natal não eram satisfatórias. Considerações Finais: ressalta-se a relevância do acesso ao pré-natal de qualidade, com ações que proporcionem escolhas seguras, esclarecendo dúvidas e anseios da futura mãe, tranquilizando-a para o momento do parto.

Descritores: Gestantes; Parto; Pessoal de saúde.

ABSTRACT: Aim: to know the factors that influence the decision of the parturition mode of pregnant women attending Juazeiro-Bahia, Health Unit. Method: qualitative research if character exploratory-descriptive, developed with pregnant women followed in the Family Health Unit of Juazeiro-BA, conducted between March and June, 2010. Twelve pregnant women, with aged over 18 years, participated in the semi-structured interviews. For the categorization of the material, it was used content analysis. Results: most of them opted for normal parturition because has a rapid recovery. Previous experience influenced in parturition choice, whether herself or others. Among the influences reported, stood his mother, health professionals and the media. Noted that the information given in prenatal were unsatisfactory. Final Thoughts: it emphasizes the importance of access to a care quality prenatal, with actions that provide safe choices, clarifying doubts and reassures of the future mother, reassuring her to the time of parturition.

Descriptors: Pregnant women; Parturition; Health staff.

RESUMEN: Objetivo: conocer los factores que influyen en la decisión del tipo de parto de las mujeres embarazadas en Juazeiro-BA. Método: investigación cualitativo con carácter

\footnotetext{
${ }^{1}$ Enfermeira. Doutora em Psicologia. Docente do Colegiado de Enfermagem. Universidade Federal do Vale do São Francisco - UNIVASF. E-mail: susanne.costa@univasf.edu.br

${ }^{2}$ Enfermeira. Especialista em Saúde Pública. Hospital Regional de Juazeiro-BA. E-mail: natxinhaacg@hotmail.com

${ }^{3}$ Enfermeira. Especialista em Saúde Pública e Obstetrícia. Secretaria Municipal de Saúde de Juazeiro-BA. Email: bruna_armentano@hotmail.com
} 


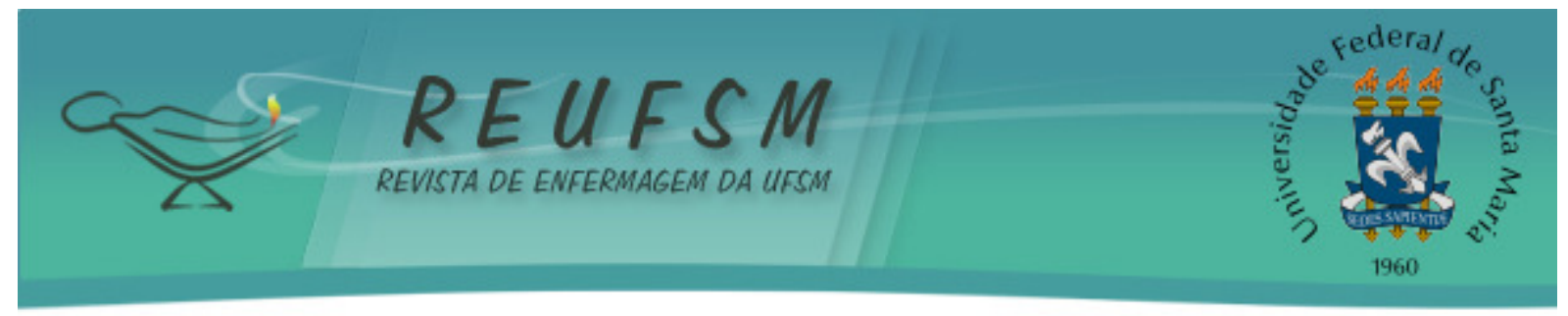

exploratorio-descriptivo, desarrollado con mujeres embarazadas acompañadas en la Unidad de Salud de la Familia, entre marzo y junio de 2010. Participaron de las entrevistas semiestructuradas 12 mujeres embarazadas con edad igual o superior a 18 años, y para la clasificación de los materiales, utilizó el análisis de contenido. Resultados: la mayoría optaron por parto natural debido a la rápida recuperación. La experiencia anterior influye en la elección del parto. Entre las influencias reportadas, estaban la madre, profesionales de la salud y medios de comunicación. Tomó nota de que la información contenida en prenatal no era satisfactoria. Consideraciones finales: se destaca la importancia del acceso a un prenatal de calidad, con acciones que ofrecen opciones seguras, aclarando dudas de la madre y tranquilizándola para el parto.

Descriptores: Mujeres embarazadas; Parto; Personal de salud.

\section{INTRODUÇÃO}

A gravidez é um dos determinantes do estado de saúde da mulher, sendo em algumas situações o único momento de contato que a mulher em idade reprodutiva terá com os serviços de saúde, tratando-se de oportunidade ímpar para uma assistência direcionada à promoção da saúde da mulher, orientação e rastreamento de enfermidades. ${ }^{1}$

A gestação significa um período diferente e especial, sendo configurado por incertezas, dúvidas e inseguranças, principalmente para as primigestas, visto que nunca passaram pela experiência. Em muitos casos, a gestante não participa da discussão acerca da escolha da via de parto, sendo informada apenas sobre a decisão médica final. 0 Brasil apresenta altas taxas de incidência de parto cesáreo (36,4\%) quando comparado a vários países do mundo como os EUA (24,7\%), Canadá (19,5\%), Dinamarca $(13,1 \%)$ e Austrália $(7,5 \%){ }^{2}$

A decisão acerca da via de parto é influenciada por diversos fatores como os riscos e benefícios, possíveis complicações e repercussões futuras. Portanto, as mulheres devem receber informações precisas para que possam fazer valer um dos elementos do Programa de Humanização no Pré-natal e Nascimento: o direito de livre escolha da via de parto, que deverá ser respeitado, especialmente, quando estas forem devidamente orientadas e acompanhadas durante todo o processo de gestação e parto. ${ }^{3}$

A expectativa das mulheres a respeito da escolha do tipo de parto tem relação com o conhecimento das mesmas sobre o assunto e as informações que são tratadas pelos profissionais da área de saúde. Portanto, torna-se importante a troca de conhecimentos durante a realização do pré-natal, não somente com o intuito de informar às gestantes, mas também como meio de interação entre o profissional e a cliente, possibilitando o esclarecimento de dúvidas, reduzindo assim a ansiedade das mulheres em relação ao momento do parto e ao período gestacional. ${ }^{4}$

Sabe-se que é fundamental para a decisão da via de parto pela gestante uma maior aproximação dela com o profissional, garantindo uma atenção integral e de qualidade à mulher, esclarecendo suas dúvidas e anseios no que se diz respeito aos aspectos da gestação, parto e puerpério. A responsabilidade e o papel do profissional na promoção da saúde das mulheres no ciclo gravídico-puerperal, na educação em saúde e na assistência ao processo parir/nascer é uma necessidade que urge por mudanças. ${ }^{5}$

Sendo assim, torna-se relevante entender quais os fatores que realmente influenciam as gestantes na decisão da via de parto. A partir desse conhecimento pode-se direcionar a atenção e o cuidado dos profissionais de saúde durante o pré-natal para o esclarecimento de dúvidas das futuras mães, fazendo com que estas decidam com confiança a via de parto pela qual seus filhos nascerão.

Atualmente, com a proposição da humanização do parto, é importante destacar que os profissionais que acompanham o pré-natal, em especial os enfermeiros, possuem importante papel, permitindo que as mudanças efetivamente ocorram. Para tal, é necessário agregar ao cuidado ações educativas e humanizadoras visando a um parto saudável, desconstruindo mitos 


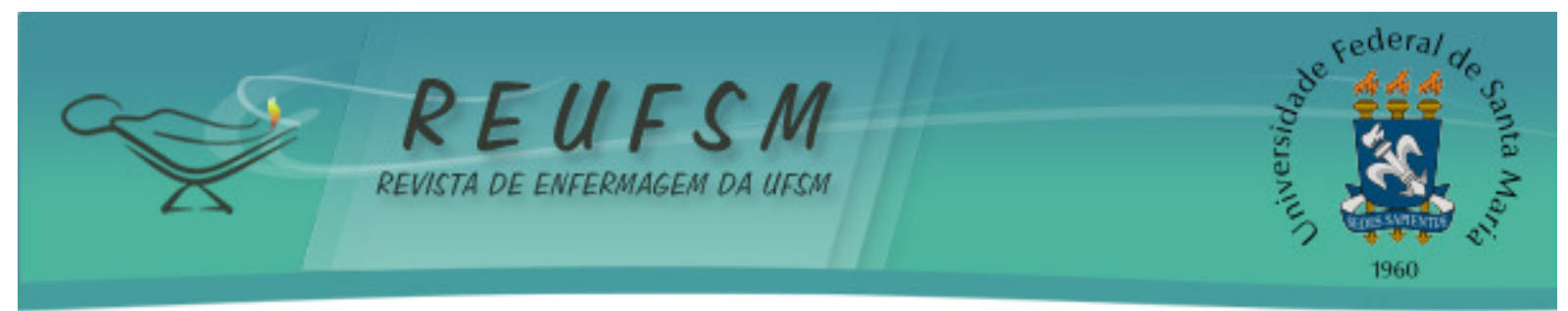

correntes que interferem neste momento. ${ }^{5} \mathrm{~A}$ partir da aproximação com gestantes e puérperas, percebeu-se a ansiedade das mesmas em relação à via e ao momento do parto, além de informações precárias no que diz respeito a tais fatores, sendo esta uma realidade a ser pensada.

Muitas mulheres ainda sentem medo de parirem por via vaginal, principalmente por temerem as consequências que podem advir desta via de parto, como o desencadeamento de incontinência urinária e fecal, distopias genitais e até lacerações perineais importantes. Este anseio pode ser multiplicado pelo desconhecimento ou mesma ausência de diálogo com os profissionais de saúde que as acompanham no pré-natal, pelo não esclarecimentos das dúvidas em relação ao momento e ao tipo de parto, tornando-se necessária uma maior aproximação entre o profissional e a paciente no intuito de fornecer informações que diminuam a ansiedade e insegurança das mesmas. ${ }^{6}$

Diante dessa realidade, estabeleceu-se como questão de pesquisa: Quais fatores influenciam na decisão pelo tipo de parto para gestantes atendidas em uma Unidade de Saúde localizada no município de Juazeiro-Bahia (BA)? Sabe-se que ainda há poucos estudos a respeito do tema ${ }^{2,4}$, embora seja um tema relevante e atual. Urge que novos estudos sejam realizados e que a discussão seja ampliada, na tentativa de melhorar o atendimento e as condições que levam uma mulher a escolher conscientemente a via de nascimento de seu filho.

Em razão do exposto, o estudo objetivou conhecer os fatores que influenciam na decisão da via de parto de gestantes atendidas em uma Unidade de Saúde de Juazeiro-BA. Destarte, o trabalho visa contribuir no atendimento à gestante, demonstrando aos profissionais de saúde e às próprias a importância das orientações do pré-natal acerca dos tipos de parto, possibilitando que as informações recebidas cooperem para uma tomada de decisão de forma crítica e segura sobre a via de parto. 0 estudo oferecerá elementos que possibilitarão o aperfeiçoamento de programas de atendimento às gestantes, bem como contribuirão para a capacitação dos profissionais que assistem as mesmas durante o pré-natal.

\section{MÉTODO}

Trata-se de estudo descritivo-exploratório, de abordagem qualitativa, desenvolvido entre março e junho de 2010 com 12 gestantes atendidas em um serviço de pré-natal de uma unidade de saúde do município de Juazeiro-BA, que obedecessem aos seguintes critérios de inclusão: idade igual ou superior a 18 anos; confirmação de gravidez, independente do tempo gestacional; acompanhamento pelo programa de pré-natal do serviço de saúde em questão.

A seleção foi feita com a ajuda da equipe de saúde, que indicou as mulheres que estavam realizando acompanhamento pré-natal à época da coleta e se enquadravam nos critérios. As entrevistas aconteceram em uma sala existente no serviço, designada para este fim. As gestantes tiveram garantido o sigilo e a confidencialidade das informações, respeitando os aspectos éticos baseados na Resolução 196/96 do Conselho Nacional de Saúde. ${ }^{7}$ Por este motivo, foram identificadas por nomes de flores, já que como elas, o momento da gravidez e parto é singelo, forte e marcante. O estudo foi encaminhado ao Comitê de Ética em Pesquisa (Certificado de Apresentação para Apreciação Ética - CAAE - 0288.0.099.000-09) e somente após aprovação iniciaram-se os procedimentos de coleta. O aceite de participação foi documentado mediante a assinatura do Termo de Consentimento Livre e Esclarecido.

A coleta de dados foi realizada com aplicação de formulário estruturado, versando sobre questões para caracterização da amostra quanto aos dados sociodemográficos, como também através de entrevista semiestruturada, guiada por tópicos que tratavam sobre o conhecimento acerca dos tipos de parto, bem como os fatores que influenciavam as mesmas no que tange a esta escolha. O tempo médio de duração das entrevistas foi de 17 minutos. Durante a sua execução, apenas a participante e o entrevistador permaneciam no ambiente. Todo o conteúdo foi gravado em aparelho MP3, com posterior transcrição. 


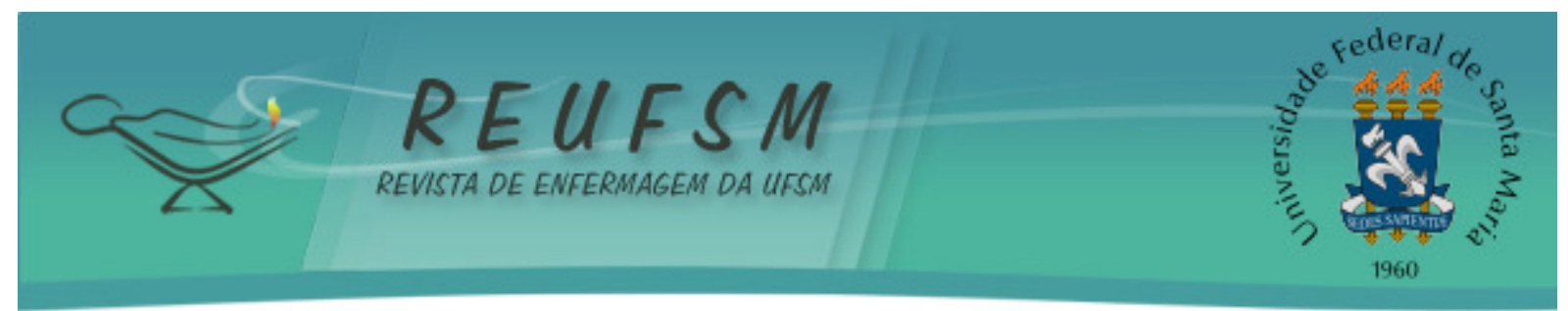

Os discursos foram analisados pela Análise de Conteúdo. Em primeiro lugar, os dados foram organizados através da leitura flutuante, com posterior exploração do material e codificação ${ }^{8}$, culminando com a formação de duas categorias: "a decisão do tipo de parto" e "as influências na decisão do tipo de parto".

\section{RESULTADOS E DISCUSSSÕES}

As idades das gestantes que participaram do estudo variaram entre 19 e 34 anos, com média de 23 anos. No que diz respeito à situação conjugal das gestantes entrevistadas, todas tinham a presença do companheiro, sendo que a maioria vivia em união consensual. $\mathbf{O}$ grau de escolaridade era relativamente baixo. Somente uma gestante havia começado o ensino superior, cinco concluíram o ensino médio, duas terminaram o ensino fundamental, três delas possuíam fundamental incompleto e uma não era alfabetizada. No que diz respeito aos aspectos sociodemográficos relacionados à gravidez, sabe-se que há interferência pela chegada de um filho na trajetória acadêmica das mulheres, o que se reflete nos altos índices da baixa escolaridade entre mães jovens, em decorrência de evasão, abandono e dificuldade de retorno à escola após o nascimento da criança. ${ }^{9}$

Com relação à ocupação, a grande maioria (dez mulheres) não trabalhava fora de casa, tendo como atividade o cuidado com o lar e os filhos. Apenas duas trabalhavam fora de casa como comerciárias. Embora não tenha sido objeto desta pesquisa conhecer os motivos que levavam as participantes a não terem vínculo empregatício, sabe-se que a maternidade ainda configura-se como uma grande responsabilidade para a mulher, o que muitas vezes dificulta que esta saia de casa para trabalhar fora, especialmente em algumas camadas sociais. ${ }^{10}$

Quanto ao número de gestações e paridade, a maioria (sete) eram multíparas e cinco eram primigestas. No que se refere ao número de filhos, três tinham dois filhos; outras três tinham um filho, e apenas uma possuía três filhos; as demais ainda não tinham filhos. Sabe-se que nas famílias com maior número de filhos e com mais idade, as gestantes tendem a procurar menos atendimento para os cuidados de saúde, sendo importante a localização e busca ativa dos serviços de saúde na procura pelas mesmas para que iniciem o pré-natal o mais precocemente possível. ${ }^{11}$

Encontrou-se neste estudo que pouco mais da metade das mulheres iniciaram a realização das consultas e o acompanhamento pré-natal no primeiro trimestre da gestação. Este deve ser iniciado o mais precocemente possível, devendo ser encerrado após o $42^{\circ}$ dia de puerpério. É importante que seja realizado um trabalho de captação e educação das gestantes para buscar o serviço de saúde tão logo suspeite da gravidez, pois o pré-natal pode contribuir para que a manutenção da saúde da mulher e do concepto aconteça. ${ }^{12}$

No que se refere às intercorrências na gestação atual, dez gestantes afirmaram ter sido acometidas, sendo que as mais relatadas foram traumas por quedas e hipertensão. A hipertensão está associada a um aumento significativo de complicações perinatais e risco para desfecho perinatal desfavorável, como Apgar baixo no $1^{\circ}$ e $5^{\circ}$ minutos, infecção neonatal e prematuridade, entre outros, merecendo atenção especial quando do seu achado. ${ }^{13}$

Ao serem indagadas sobre o profissional que realizava as consultas pré-natais no serviço de saúde, seis gestantes afirmaram ser atendidas apenas pelo enfermeiro da unidade, enquanto as outras seis alegaram ser acompanhadas pela equipe multiprofissional (médico e enfermeiro). 0 acompanhamento e as consultas pré-natais, em geral, envolvem procedimentos simples e uma equipe multidisciplinar de saúde que preste o cuidado integral à gestante, dedicando-se e escutando a mesma, oferecendo-lhe apoio e estabelecendo uma relação de confiança, ajudando-a conduzir a experiência da maternidade com mais autonomia. ${ }^{14}$

Para apreciação dos resultados das entrevistas, os discursos foram agrupados em duas categorias, de acordo com a aproximação da temática abordada nas perguntas do roteiro que guiou o presente estudo. A primeira categoria trata do tipo de parto escolhido pelas gestantes, enquanto a segunda revela que fatores influenciaram nesta decisão. 


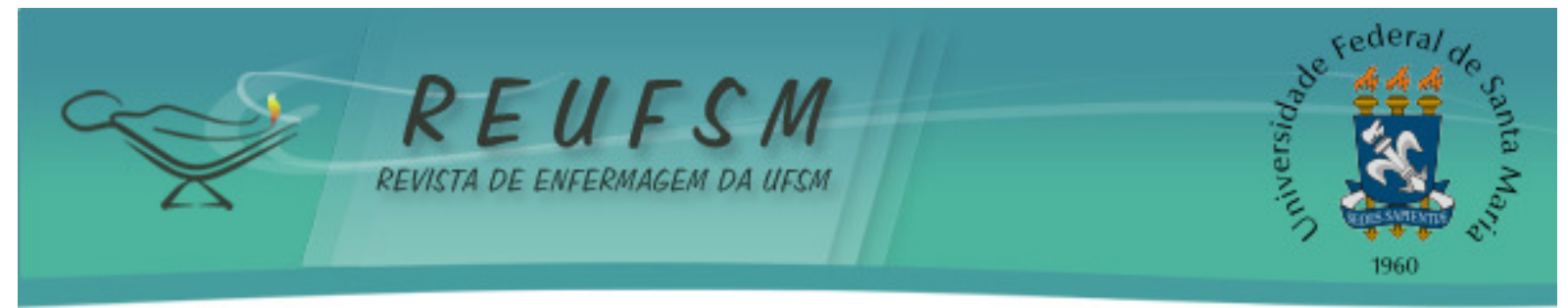

\section{A decisão do tipo de parto}

Inicialmente, as mulheres foram indagadas sobre o tipo de parto que desejavam ter. Percebeu-se, então, que esta decisão desperta muitos sentimentos e dúvidas nesse período conflituoso que é a gestação. Portanto, nesta categoria, estão contidos os discursos referentes aos motivos que delineavam a escolha em relação à via de parto e as principais justificativas no que diz respeito a essa decisão.

A preferência pelo parto natural, que ocorre na grande maioria das mulheres, foi justificada pelo fato de que o mesmo possibilita uma cicatrização e recuperação mais rápida, favorecendo retorno célere às atividades diárias, além das inconveniências causadas pela cesariana, quais sejam as dores e desconfortos que ocorrem geralmente após o nascimento da criança. A seguir encontram-se recortes que podem exemplificar esta discussão:

Não tive nenhuma experiência com parto antes, pois esse é o meu primeiro filho, mas as pessoas dizem que é o melhor. Dizem que o normal dói na hora e depois a dor passa, já o cesáreo para a mulher se recuperar é mais difícil. (Alecrim)

O parto normal me deixa muito bem após esse momento, porque eu já consigo caminhar, arrumar minha casa, cuidar dos meus filhos $e$ fazer todas as minhas atividades. Além do mais, já pari cinco filhos de parto normal e nunca passei por nenhuma situação difícil, então já perdi o medo. (Margarida)

Observa-se que a experiência anterior é bastante influente na escolha atual, quer seja dela própria, quer seja de outrem. Aquelas que já pariram por via natural permaneciam acreditando ser esta a melhor forma. Já as mulheres que nunca passaram pela experiência, demonstram que possuem muitas dúvidas a respeito deste momento, mas, influenciadas por quem já vivenciou, acreditam ser o melhor a fazer.

Entende-se que são inúmeros os benefícios do parto normal tanto para a mãe quanto para o bebê, e vão desde uma melhor e rápida recuperação da mulher e menor risco de aquisição de infecção hospitalar, até uma incidência menor de desconforto respiratório para o bebê. Sendo assim, o parto normal proporciona a mãe uma recuperação pós-parto praticamente imediata, podendo a mesma voltar aos seus afazeres bem mais precocemente, sem a influência da anestesia e sem as dores da incisão cirúrgica, feita na cesariana. ${ }^{15}$

De acordo com dados do Sistema de Informações de Nascidos Vivos (SINASC) do Município de Juazeiro-BA em 2012, o percentual de partos vaginais realizados foi quase que o dobro de cesarianas. Tal fato demonstra que o anseio em parir por via vaginal tem sido compatível com a prática. ${ }^{16}$

Embora fossem minoria, as gestantes que tiveram preferência pela operação cesariana justificaram tal escolha a partir de alguma experiência anterior com parto normal que não foi exitosa ou mesmo pelo medo de sofrer e sentir dor no parto natural, acreditando que durante a realização da cesariana, a mulher recebe uma assistência mais cuidadosa, como pode ser percebido nos recortes a seguir:

Sofri muito na minha primeira gravidez, ou melhor, no momento do parto, senti muita dor, levei muitos pontos. Não tive muita assistência, pois não tinha nenhum médico no local. Senti muito medo naquele momento, fiquei com um trauma muito grande. (Alfazema) Apesar de ser minha primeira gestação, tenho muito medo do parto normal. Minha mãe sofreu muito no meu nascimento e quando ela 


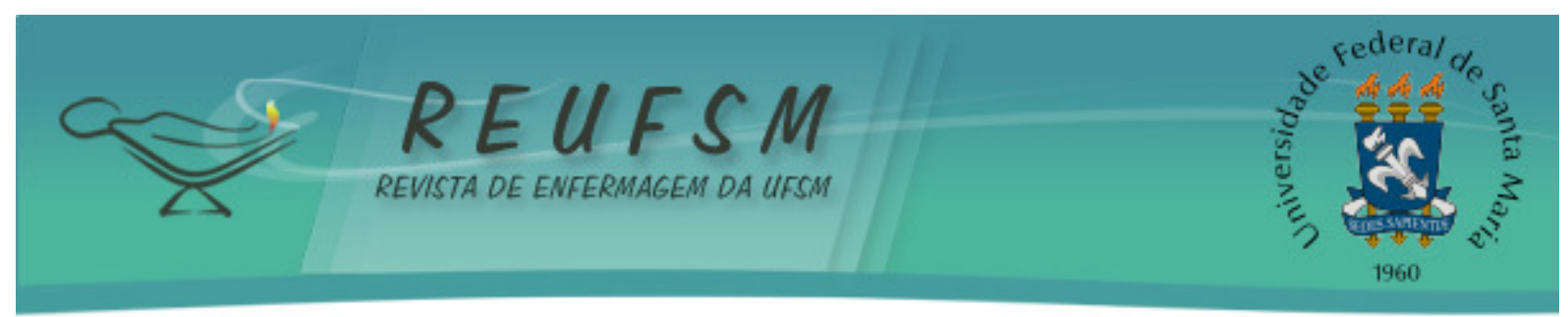

me conta tudo o que aconteceu, fico horrorizada. Eu era muito grande, então ela levou muitos pontos. Não deu nem tempo de dar a anestesia, a dor e o sofrimento foram grandes. (Perpétua)

Em nossa sociedade, muitas mulheres que optam por parir a partir da operação cesariana o fazem por imaginarem que esse tipo de parto é indolor e preserva a anatomia da vagina para as relações sexuais. ${ }^{2}$ Até o início do século XIX, a operação cesariana implicava em elevados índices de morte materna e fetal. Atualmente, com a evolução dos conhecimentos anestésicos e de sutura uterina, representa uma excelente conquista para a área da obstetrícia. ${ }^{17}$

Algumas décadas atrás, o parto cesáreo era realizado somente em ocasiões excepcionais, ou seja, em situações de risco de vida para a mãe e para o feto, e a quase totalidade das mulheres resistiam a sua realização. Ultimamente, a elevação da incidência de cesarianas é um fenômeno mundial, sendo o Brasil reconhecido como um dos países com maiores índices e tido como um dos exemplos mais claros de realização deste procedimento mesmo sem indicações. ${ }^{18}$

É evidente a crescente elevação nas taxas de cesarianas sem indicação médica, tanto nos países desenvolvidos quanto nos subdesenvolvidos. Apesar de a grande maioria das gestantes relatarem que sua opção seria pela via de parto vaginal devido aos benefícios que este pode trazer após sua realização, principalmente pela rápida recuperação, algumas ainda demonstraram o desejo de realização da cesariana. ${ }^{19}$

É válido destacar que, a opinião do profissional no momento do parto, também deve ser respeitada, visto que pode-se cair no erro de escolher uma forma de parir que não seja indicada para o momento.

\section{As influências na decisão do tipo de parto}

Investigando a respeito da forma como as gestantes decidiram à via de parto que seus filhos nasceriam e se houve influência de alguém nesta decisão, ficou evidente que para algumas mulheres houve a participação de influências externas no processo decisório pelo tipo de parto, enquanto outras decidiram sozinhas a partir do sucesso dos partos anteriores. Deve ser levado em consideração, pelos profissionais de saúde, o saber popular, que muitas vezes exerce influência nesta escolha.

As experiências anteriores das próprias mulheres ou das pessoas próximas, exitosas ou não, acabam servindo como espelho e induzindo a mulher a escolher seu tipo de parto, não levando em consideração que cada mulher e cada gestação é diferente, e aquilo que é indicado para uma futura mãe ou gestação, nem sempre é recomendado para outra.

É evidente a grande participação dos familiares e, principalmente, a mãe da gestante nesse processo, influenciando a partir de suas vivências e experiências com o parto. Também é notória a influência das amigas, da mídia e dos profissionais de saúde.

Eu decidi pelo que já escutei sobre os tipos de parto. De certa forma, houve influência das pessoas mais próximas. Minha mãe e minha tia tiveram parto cesáreo e sofreram muito, sentiram muita dor. Elas me aconselham a parir normal. (Alecrim)

A partir do que já ouvi de outras pessoas, já que nunca passei pela experiência do parto antes. Uma pessoa que me influenciou muito foi minha mãe. Ela teve dois filhos por parto normal e um por cesáreo, que foi o terceiro filho. Ela sofreu muito porque os pontos romperam e ela adquiriu uma infecção, por isso demorou muito tempo para se recuperar. De certa forma ela tem medo que isso aconteça comigo também. (Jasmin) 


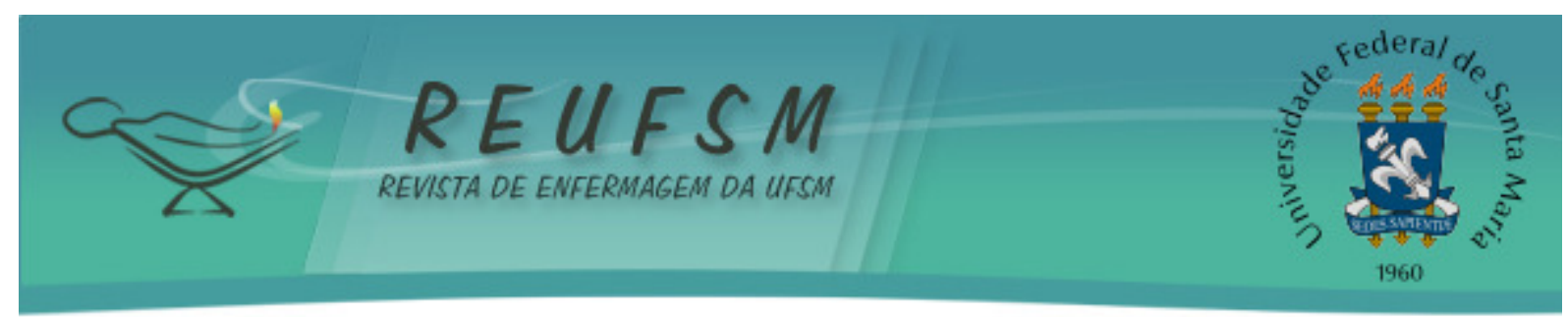

Como eu nunca pari antes, decidi através do que escuto na televisão, no posto de saúde, e a partir do que minhas amigas $e$ familiares me passaram a respeito do parto. (Violeta)

A aparente liberdade de escolha assegurada à mulher, muitas vezes, é sonegada pela manipulação das informações prestadas pelos profissionais de saúde que acompanham o período gestacional através do pré-natal. A escolha em relação ao tipo de parto é um direito, porém a gestante necessita receber informações precisas a respeito das vias de parto para que possa tomar decisões com autonomia e de forma segura. Nesse sentido, o diálogo entre o profissional de saúde e a mulher permite a negociação e a troca de informações como forma de garantir benefícios na assistência ao parto e o favorecimento da liberdade de expressão da gestante. . $^{2,4}$

A decisão pela via de parto recebe muitas influências, tanto dos profissionais de saúde, que muitas vezes acabam por decidir por conta própria o tipo de parto que a mulher deverá ter, quanto pelos próprios familiares, com especial destaque para a mãe da gestante. Tais fatores mostram a importância do papel da mulher como portadora do direito de decisão a respeito da via de parto da sua preferência. Portanto, cabe a equipe de saúde, em especial aqueles que realizarão o parto, aceitar a decisão da sua paciente ou interferir nesta quando em situação de risco para mãe e/ou o feto.

No entanto, as gestantes que participaram deste estudo revelaram que as informações perpassadas no pré-natal não eram satisfatórias, visto que a maioria afirmou nunca ter recebido nenhum tipo de informação sobre vias de parto durante a consulta, enquanto as que receberam disseram que isso se deu de forma imprecisa e insuficiente.

Nunca recebi orientações sobre os tipos de parto nas consultas de pré-natal. O que sei é o que já vivi e o que escuto das pessoas, dos amigos e dos familiares. (Girassol)

Os profissionais fizeram uma palestra sobre os tipos de parto enquanto as gestantes esperavam a consulta, e falaram em relação ao cesáreo, sobre as complicações que podem acontecer como o rompimento dos pontos e o risco de infecção, além da recuperação que demora mais. (Orquídea)

O conhecimento das gestantes, em relação às vias de parto, está relacionado ao modo como as informações sobre o assunto são disponibilizadas para as mesmas. Nesse sentido, o pré-natal existe como um instrumento educativo de alto potencial, porém ainda é pouco entendida a sua importância. Faz-se necessária a participação de uma equipe multidisciplinar que desempenhe atividades e informações a respeito do período gestacional e do momento do parto, visando diminuir a ansiedade e a insegurança das gestantes, além de proporcionar maior relação interpessoal entre profissional e paciente..$^{2,4}$

O acompanhamento pré-natal é responsável por cuidar da saúde física e mental das mães e dos bebês, fazendo com que as dúvidas referentes à gestação e maternidade sejam esclarecidas. Portanto, cabe aos profissionais e as equipes de saúde orientar e esclarecer acerca destas questões, fazendo com que as gestantes sintam-se seguras no que se refere ao processo gestacional e parto. Ressalta-se que a prática assistencial do profissional, em especial o enfermeiro, demarca a potencialidade que este tem para que a humanização do processo parir/nascer ultrapasse o campo do direito, quebrando resistências para sua efetiva implantação nos serviços de saúde. ${ }^{5}$ 


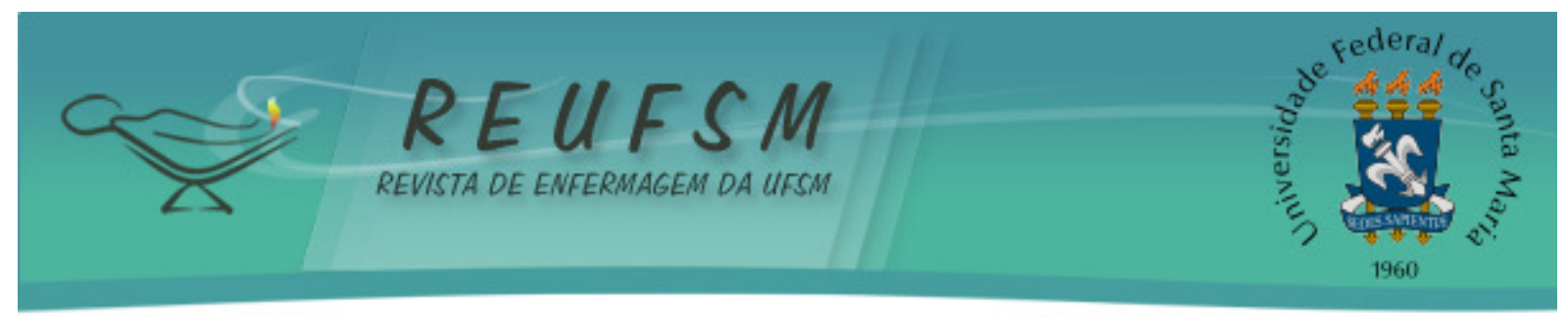

\section{CONSIDERAÇÕES FINAIS}

O desejo pelo parto natural foi demonstrado pela maioria das mulheres, com a justificativa de que o mesmo favorece uma recuperação e cicatrização mais rápida, possibilitando um retorno precoce às atividades, quando comparado com o pós-parto da cesariana. As gestantes que optaram pela operação cesariana evidenciaram tal anseio a partir de experiências que não foram bem sucedidas com parto vaginal, além do desejo de realização da laqueadura tubária, que seria facilitado por um parto deste tipo e pelo medo da dor e sofrimento da parturição normal, o que, em seus imaginários, era algo quase que insuportável.

Constatou-se, então, que alguns fatores próprios da gestante, como as experiências anteriores com o parto, sejam elas bem ou mal sucedidas, bem como a influência da mãe, das amigas, da mídia, dos profissionais de saúde e de familiares, a partir de suas vivências com a gestação, exerciam importante papel na decisão do tipo de parto para as gestantes.

Pôde-se perceber também a falta de apoio dos profissionais de saúde, durante o período gestacional, no momento da realização das consultas pré-natais, no que tange ao repasse de informações a respeito das vias de parto. Portanto, é no período pré-natal que o profissional que o realiza apresenta papel relevante como educador em saúde, oferecendo apoio e segurança, fazendo com que a mulher decida de forma segura a via de parto pela qual seu filho nascerá. Porém, no sistema de saúde vigente no Brasil, nem sempre esta escolha é respeitada. Na prática, escolhe o tipo de parto aquela que pode pagar pelo serviço.

Assim, a discussão dos resultados encontrados ratifica o conhecimento contido na literatura de enfermagem no que concerne ao assunto, que possibilitará a revisão e aperfeiçoamento de programas de atendimento às gestantes. É necessário, então, capacitar os profissionais que as acompanham no pré-natal, visto que foi evidenciado a falta de participação da equipe multidisciplinar de saúde de forma intensa no período gestacional, a partir da realização de consultas pré-natais humanizadas, incluindo orientações e atendimentos dignos neste período simbólico que é a gestação para a vida das mulheres e de suas famílias.

\section{REFERÊNCIAS}

1. Costa GRC, Chein MBC, Gama MEA, Coelho LSC, Costa ASV, Cunha CLF, et al. Caracterização da cobertura do pré-natal no Estado do Maranhão, Brasil. Rev Bras Enferm. 2010;63(6):1005-9.

2. Tedesco RP, Maia Filho NL, Mathias L, Benez AL, Castro VCL, Bourroul GM, et al. Fatores determinantes para as expectativas de primigestas acerca da via de parto. Rev Bras Ginecol Obstet. 2004;26(10):791-8.

3. Ministério da Saúde (BR). Secretaria de Políticas de Saúde. Área técnica de saúde da mulher. Parto, aborto e puerpério: assistência humanizada à mulher. Brasília (DF): Ministério da Saúde; 2001.

4. Oliveira SMJV, Gozalez Riesco ML, Rosas Miya CF, Vidotto P. Tipo de parto: expectativas das mulheres. Rev Latinoam Enferm. 2002;10(5):667-74.

5. Velasque EAG, Pradebon VM, Cabral FB. O enfermeiro no processo parir/nascer: estratégia de cuidado e humanização do parto. Rev Enferm UFSM [Internet]. 2011 [acesso em 2013 mar 8];1(1):80-7. Disponível em: http://cascavel.ufsm.br/revistas/ojs2.2.2/index. php/reufsm/article/view/1991/1514.

6. Gama AS, Giffin KM, Angulo-Tuesta A, Barbosa GP, d'Orsi E. Representações e experiências das mulheres sobre a assistência ao parto vaginal e cesárea em maternidades pública e privada. Cad Saúde Pública. 2009;25(11):2480-8. 


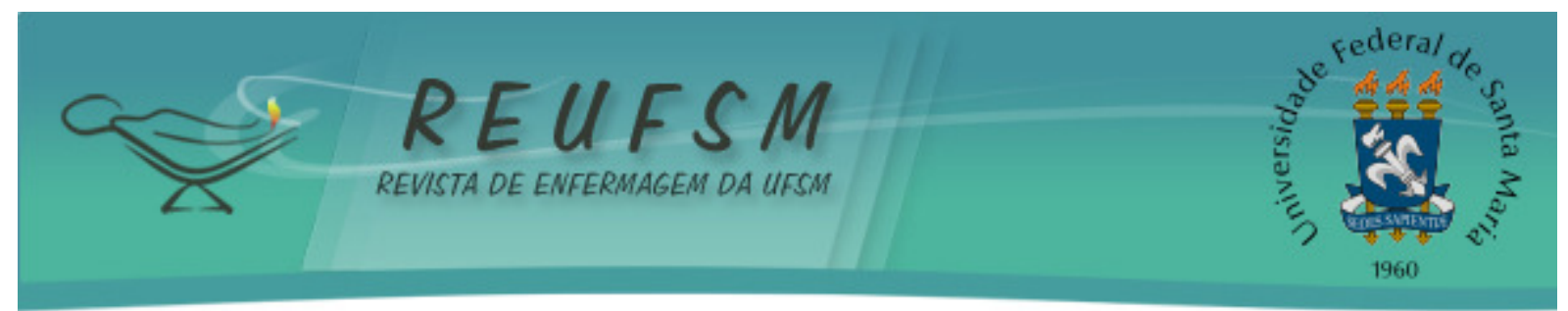

7. Ministério da Saúde (BR) Conselho Nacional de Saúde. Resolução CNS $n^{\circ} 196$, de 10 de outubro de 1996. Diretrizes e normas regulamentadoras de pesquisa envolvendo seres humanos. Brasília (DF); 1996.

8. Bardin L. Análise de conteúdo. Lisboa: Edições 70; 2004.

9. Costa MCO, Santos CAST, Nascimento Sobrinho C, Moura MSQ, Souza KEP, Assis DR. Gravidez na adolescência: associação de variáveis sociodemográficas e biomédicas materna com resultado neonatal. Rev Baiana Saúde Pública. 2005;29(2):300-12.

10. Lopes CMS. Direito do trabalho da mulher: da proteção à promoção. Cad Pagu. 2006;(26):405-30.

11. Costa JSD, Cesar JA, HaagI CB, Watte G, Vicenzi K, Schaefer R. Inadequação do prénatal em áreas pobres no Nordeste do Brasil: prevalência e alguns fatores associados. Rev Bras Saúde Matern Infant. 2013;13(2):101-9.

12. Federação Brasileira das Associações de Ginecologia e Obstetrícia. Assistência pré-natal parte II. Rev Assoc Med Bras. 2007;53(6):479-81.

13. Oliveira CA, Lins CP, Sá RAM, Chaves Netto H, Bornia RG, Silva NR, et al. Síndromes hipertensivas da gestação e repercussões perinatais. Rev Bras Saúde Matern Infant. 2006;6(1):93-8.

14. Assistência pré-natal: manual técnico. Schirmer J, Parras AP, Leocádio E, Formiga Filho JFN, Fajardo ML, Costa Neto MM, et al, colaboradores. $3^{a}$ ed. Brasília (DF): Secretaria de Políticas de Saúde; 2000. 66 p.

15. Ministério da Saúde (BR). Secretaria de Políticas de Saúde. Área Técnica de Saúde da Mulher. Parto normal: mais segurança para a mãe e para o bebê. Brasília (DF): Ministério da Saúde; 2005.

16. Ministério da Saúde (BR). Secretaria de Vigilância em Saúde. Uma análise dos nascimentos no Brasil e regiões. Brasília (DF): Ministério da Saúde; 2004.

17. Souza E, Guerzet EA, Camano L. Parto cesáreo. In: Bortoletti FF, Moron FM, Bortoletti Filho J, Nakamura U. Psicologia na prática obstétrica: abordagem interdisciplinar. São Paulo: Manole, 2007. p. 284-5.

18. Sakae TM, Freitas PF, D'orsi E. Fatores associados a taxas de cesárea em hospital universitário. Rev Saúde Pública. 2009;43(3):472-80.

19. Mandarino NR, Chein MBC, Monteiro Júnior FC, Brito LMO, Lamy ZC, Nina VJS, et al. Aspectos relacionados à escolha do tipo de parto: um estudo comparativo entre uma maternidade pública e outra privada, em São Luís, Maranhão, Brasil. Cad Saúde Pública. 2009;25(7):1587-96.

Data de recebimento: 03/05/2013

Data de aceite: $28 / 11 / 2013$

Contato com autor responsável: Susanne Pinheiro Costa e Silva

Endereço postal: Av. José de Sá Maniçoba, Sn, Centro. Caixa Postal 252, CEP 56304-205 -

Petrolina-PE, Brasil.

E-mail: susanne.costa@univasf.edu.br 